\title{
Diagnostic Accuracy of Intraoperative Frozen Sections in the Diagnosis of Central Nervous System Lesions: A Hospital-Based Study
}

\author{
Win $T T^{a}$, Tuan Sharif $S E^{b}$ Mat Zin $A A^{b}$ \\ aathology Division, School of Medicine, International Medical University, Kuala Lumpur, Malaysia

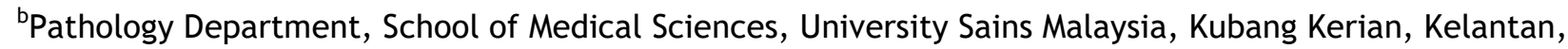 \\ Malaysia
}

\section{ABSTRACT}

Introduction: Intraoperative frozen section (FS) is an important tool in the management of neoplastic and non-neoplastic central nervous system (CNS) lesions. Although the final pathological diagnosis is based on the findings in paraffin tissue sessions, interpreting FS of CNS lesion is to assist the neurosurgeon in making the accurate judgment regarding the nature of the lesion and tissue adequacy. This study was to evaluate the agreement between FS and paraffin sections (PS) results; and to highlight the possible causes of error in discrepancy between FS and PS. Materials \& Methods: This is a retrospective study of 85 cases of FS. H\&E stained sections of both FS and PS of all these cases were reviewed with their histopathological reports. FS and PS results were compared. Possible causes of errors were reviewed and recorded. Results: Out of 85 cases; 76 cases $(89.4 \%)$ showed no discrepancy, 2 cases $(2.4 \%)$ minor discrepancy and 7 cases (8.2\%) discrepancy. Sensitivity and specificity of FS were $90.1 \%$ and $85.7 \%$ respectively. Positive predictive value was $97.0 \%$ and negative predictive value was $63.1 \%$. The false positive rate was $14.2 \%$ and false negative rate was $36.8 \%$. The overall accuracy of FS was $89.4 \%$. Conclusion: Our results showed high accuracy and specificity of FS. Therefore, FS is still useful, an effective tool for neurosurgeon although there are some challenges for histopathologists in reporting FS. The commonest discrepancy was seen between reactive gliosis and low-grade glioma. Over-diagnosis or under-diagnosis of FS can be reduced by closed cooperation among pathologist, neurosurgeon and radiologist.

KEYWORDS: Diagnostic accuracy, cause of error, false positive, false negative, discrepant

\section{INTRODUCTION}

Intraoperative frozen section (FS) plays a major role and PS. Accuracy of FS can be achieved by the in the surgical management of patients with evaluation of discrepancies followed by identifying neoplastic and non-neoplastic diseases. It provides discrepancies in reporting and resolving the the surgeon with important pathological information underlying problems. ${ }^{2}$

during the operation procedure. ${ }^{1}$ As the diagnosis on

permanent paraffin section (PS) is the gold standard, Intraoperative FS consultation is an important part of the accuracy of FS diagnosis can be documented by many neurosurgical procedures in which tissue is comparing the diagnosis made on the FS to the final being obtained for the purpose of rendering a diagnosis made on PS after a review of both FS diagnosis. ${ }^{3}$ It is an important part for management of patients with both neoplastic and non-neoplastic

Corresponding Author:

Dr. Thin Thin Win

Pathology Division

School of Medicine, International Medical University 126, Jalan Jalil Perkasa 19, Bukit Jalil, 57000 Kuala Lumpur, Malaysia

Tel No : 603-27317010

Email : thinthinwin@imu.edu.my central nervous system (CNS) lesions which are targeted for surgical biopsy or intervention. The primary goal of the intraoperative FS consultation is to ensure that adequate tissue is available for an accurate final diagnosis. ${ }^{4}$ The role of the histopathologist in interpreting FS of CNS lesions is to assist the neurosurgeon in determining the adequacy of the submitted tissue for diagnosis, to establish the 
nature and presence of the lesions and to establish the most accurate judgment of the lesions along with clinico-radiological correlation. $^{5}$

Although there are significant improvements in neuro -radiological diagnostic techniques, FS reports are still important intraoperative tool for neurosurgeons to determine the best procedure to reach the endpoint of the operation. ${ }^{6}$ The aim of this study was to evaluate the degree of agreement between the intraoperative FS reports and final histopathological diagnosis on PS; and to highlight the possible causes of error in the cases showing discrepancies between FS and PS results.

\section{MATERIAL AND METHODS}

This study is a retrospective descriptive study conducted in the Pathology Department, Hospital Universiti Sains Malaysia from January 2007 to December 2016. After retrieving histopathology records reported in the department during that period, a total 412 FS cases of various organ system diseases were collected. Among them, FS cases of all CNS lesions regardless of the type of diagnosis were selected. Haematoxylin and Eosin (H\&E) stained slides of both FS and PS of all CNS FS cases with their histopathological reports were collected. Cases with missing FS slides or PS slides and inadequate tissue sample in both FS and PS were excluded from the study. A total 85 cases of CNS lesions were finally collected with their FS slides and PS slides to be reviewed for this study. Two investigators (pathologists) independently reviewed all the slides from the cases. FS results were compared with the results of PS.

The cases were graded into three degrees of diagnosis discrepancy to clarify the accuracy of intraoperative diagnosis; i) no discrepancy (ND), ii) minor discrepancy (MD) and iii) discrepancy (D). If FS diagnosis matched exactly the diagnosis of PS with complete agreement, it was graded as 'no discrepancy'. If FS diagnosis did not match exactly PS diagnosis with partial agreement, however, it was quite close to PS diagnosis; it was graded as 'minor discrepancy'. If FS diagnosis did not match PS diagnosis with no agreement, it was graded as 'discrepancy'. To analyse specificity, sensitivity, positive predictive value (PPV), negative predictive value (NPV), false positive rate (FPR), false negative rate (FNR) and accuracy of FS results, following parameters were determined as follows:

\begin{tabular}{ll}
\hline $\begin{array}{l}\text { Cases reported with same specific } \\
\text { pathology in both FS and PS }\end{array}$ & $\begin{array}{l}\text { True } \\
\text { positive } \\
\text { (TP) }\end{array}$ \\
\hline $\begin{array}{l}\text { Cases reported with specific pathology or } \\
\text { malignancy in FS, however, there is no } \\
\text { specific pathology or malignancy in PS }\end{array}$ & $\begin{array}{l}\text { False } \\
\text { positive } \\
\text { (FP) }\end{array}$ \\
\hline $\begin{array}{l}\text { Cases reported with no specific pathology } \\
\text { in both FS and PS: }\end{array}$ & $\begin{array}{l}\text { True } \\
\text { negative } \\
\text { (TN) }\end{array}$ \\
\hline $\begin{array}{l}\text { Cases reported with no specific pathology } \\
\text { or malignancy in FS, however, there is } \\
\text { specific pathology or malignancy in PS }\end{array}$ & $\begin{array}{l}\text { False } \\
\text { negative } \\
\text { (FN) }\end{array}$ \\
\hline
\end{tabular}

Specificity, sensitivity, PPV, NPV, FPR, FNR and overall accuracy of FS were calculated by following formulas. Statistical analysis was done using SPSS software.

$\begin{array}{ll}\text { Sensitivity } & =\mathrm{TP} \times 100 / \mathrm{TP}+\mathrm{FN} \\ \text { Specificity } & =\mathrm{TN} \times 100 / \mathrm{TN}+\mathrm{FP} \\ \mathrm{NPV} & =\mathrm{TN} \times 100 / \mathrm{FN}+\mathrm{TN} \\ \mathrm{PPV} & =\mathrm{TP} \times 100 / \mathrm{FP}+\mathrm{TP} \\ \text { FPR } & =\mathrm{FP} \times 100 / \mathrm{FP}+\mathrm{TN} \\ \text { FNR } & =\mathrm{FN} \times 100 / \mathrm{FN}+\mathrm{TP} \\ \text { Accuracy } & =\begin{array}{l}\mathrm{TP}+\mathrm{TN} \times 100 / \text { Total number of } \\ \text { cases }\end{array}\end{array}$

\section{RESULTS}

From the 85 cases of FS of CNS lesions in this study, 40 cases $(47.1 \%)$ were male and 45 cases $(52.9 \%)$ were female. The ages ranged from 3 to 65 years old and mean age was 33 years old.

Out of 85 cases, 76 cases $(89.4 \%)$ showed no discrepancy, 2 cases $(2.4 \%)$ showed minor discrepancies and 7 cases (8.2\%) showed discrepancies between FS and PS results. 64 cases (75.3\%) were TP, 12 cases (14.1\%) were TN, 2 cases (2.4\%) were FP and 7 cases $(8.2 \%)$ were $\mathrm{FN}$. Sensitivity and specificity of FS were $90.1 \%$ and $85.7 \%$ respectively. PPV and NPV were $97.0 \%$ and $63.1 \%$ respectively. FPR and FNR were $14.2 \%$ and $9.8 \%$ respectively. The overall accuracy of FS was $89.4 \%$.

Out of two FP 2 cases, one case was suggestive of high-grade glioma in FS due to the presence of necrotic fragments. However, the case turned out to 
be a low-grade glioma (WHO grade I) with coagulative necrosis rather than geographic necrosis in PS (Figures 1 A, B \& C). Another case of FP showed highgrade glioma in FS; however, it showed diffuse astrocytoma (WHO grade II) in PS as large pleomorphic cells turned out to be gemistocytes.

Out of 7 cases of FN, 4 cases showed reactive gliosis in FS and turned out to be low-grade glioma (WHO I \& II) in PS. Other 3 cases showed meningioma, schwannoma and non-Hodgkin lymphoma (NHL) in PS (Figures 2 A, B \& C). Explanation of possible errors in discrepancy and minor discrepancy with FP and FN is shown in Tables I and II.

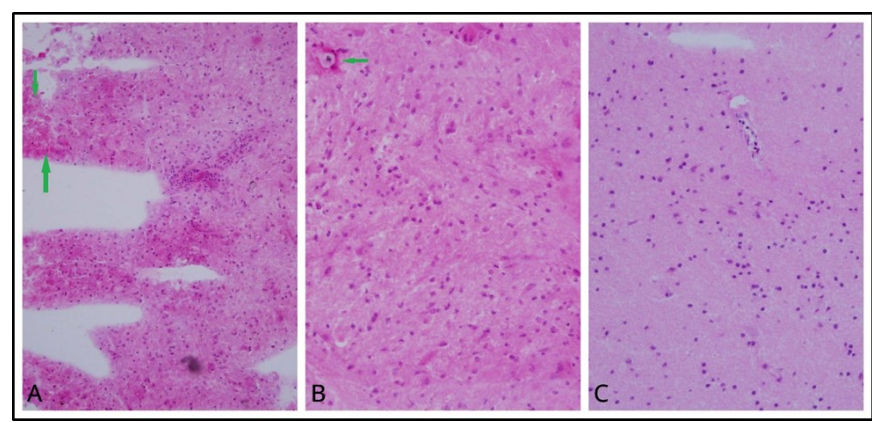

Figure 1: A case of low-grade glioma: A; Small areas of coagulative necrotic foci in FS (100X) (arrows), B; - Few mildly pleomorphic cells with mitosis (arrow) in FS which mimicked high-grade glioma (200X), C; Features of lowgrade glioma in PS (200X).

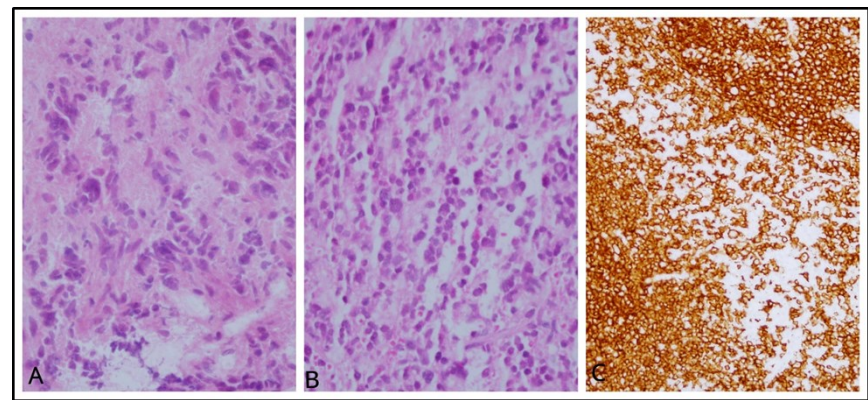

Figure 2: A case of CNS NHL: A; - (FS) Lymphoma cells are mistaken as tumour cells of high-grade glioma in FS, B; (PS) Lymphoma cells of NHL in PS, C; Tumour cells are positive for CD20 immunohistochemically. (400X)

\section{DISCUSSION}

Frozen section (FS) interpretation is one of the challenging works in the field of histopathology. The most common cause of limitation and challenge of FS interpretation is ice crystal artefact resulting in distortion of architectural details. ${ }^{7}$ The aim of reporting FS by histopathologist in the diagnosis of CNS lesions is to guide the neurosurgeon in making clinically relevant intraoperative decisions, which helps the surgeon to plan the extent of surgery and modify it accordingly. Accurate intraoperative diagnosis is based on good correlation of clinical, radiological and microscopic findings. ${ }^{8}$

Table I: Discrepancy cases between frozen section and paraffin section

\begin{tabular}{|c|c|c|c|}
\hline & $\begin{array}{l}\text { Frozen } \\
\text { section }\end{array}$ & $\begin{array}{l}\text { Paraffin } \\
\text { section }\end{array}$ & Possible error \\
\hline 1. & $\begin{array}{l}\text { Suggestive of } \\
\text { high grade } \\
\text { glioma due } \\
\text { to necrosis } \\
\text { (FP) }\end{array}$ & $\begin{array}{l}\text { Low-grade } \\
\text { glioma } \\
\text { (WHO I) }\end{array}$ & $\begin{array}{l}\text { Coagulative } \\
\text { necrotic areas in } \\
\text { FS mistaken as } \\
\text { geographic } \\
\text { necrosis }\end{array}$ \\
\hline 2. & $\begin{array}{l}\text { High grade } \\
\text { glioma (FP) }\end{array}$ & $\begin{array}{l}\text { Diffuse } \\
\text { astrocytoma } \\
\text { (WHO grade II) }\end{array}$ & $\begin{array}{l}\text { Gemistocytes in FS } \\
\text { mistaken as } \\
\text { pleomorphic } \\
\text { tumour cells }\end{array}$ \\
\hline 3. & $\begin{array}{l}\text { Reactive } \\
\text { gliosis (FN) } \\
\text { (discrepancy) }\end{array}$ & $\begin{array}{l}\text { Fibrillary } \\
\text { astrocytoma } \\
\text { (WHO II) }\end{array}$ & $\begin{array}{l}\text { Nuclear atypia and } \\
\text { increased } \\
\text { cellularity only } \\
\text { appeared in serial } \\
\text { PS }\end{array}$ \\
\hline 4. & $\begin{array}{l}\text { Reactive } \\
\text { gliosis (FN) } \\
\text { (discrepancy) }\end{array}$ & Schwannoma & $\begin{array}{l}\text { Scattered } \\
\text { Schwann cells } \\
\text { mistaken as glial } \\
\text { cells }\end{array}$ \\
\hline 5. & $\begin{array}{l}\text { Reactive } \\
\text { gliosis (FN) } \\
\text { (discrepancy) }\end{array}$ & $\begin{array}{l}\text { Low-grade } \\
\text { astrocytoma } \\
\text { (WHO II) }\end{array}$ & $\begin{array}{l}\text { Only serial } \\
\text { sections of one } \\
\text { fragment showed } \\
\text { increased glial } \\
\text { cells }\end{array}$ \\
\hline 6. & $\begin{array}{l}\text { High-grade } \\
\text { glioma (FN) } \\
\text { (discrepancy) }\end{array}$ & $\begin{array}{l}\text { Non-Hodgkin } \\
\text { lymphoma }\end{array}$ & $\begin{array}{l}\text { Lymphoma cells } \\
\text { can be confirmed } \\
\text { only with IHC } \\
\text { stains }\end{array}$ \\
\hline 7. & $\begin{array}{l}\text { Reactive } \\
\text { gliosis (FN) } \\
\text { (discrepancy) }\end{array}$ & $\begin{array}{l}\text { Anaplastic } \\
\text { astrocytoma }\end{array}$ & $\begin{array}{l}\text { Atypical small } \\
\text { cells mistaken as } \\
\text { reactive } \\
\text { lymphocytes } \\
\text { and confirmed } \\
\text { with IHC stains }\end{array}$ \\
\hline
\end{tabular}

FS: frozen section, PS: paraffin section, FP: false positive, FN: false negative

In this study, the overall accuracy of FS was $89.4 \%$. Although it was high, it was lower than the accuracy reported by Khoddami M. et al. which was $99.5 \% .{ }^{9}$ It might be due to the smaller sample size of this study. Sensitivity $(90.1 \%)$ was higher than specificity $(85.7 \%)$ as there were more TP cases than TN cases. PPV (97.0\%) was also higher than NPV (63.1\%) and it might be due to more TP cases in this study.

Table II: Minor discrepancy cases between frozen section and paraffin section

\begin{tabular}{|c|c|c|c|}
\hline & $\begin{array}{l}\text { Frozen } \\
\text { section }\end{array}$ & $\begin{array}{l}\text { Paraffin } \\
\text { section }\end{array}$ & Possible error \\
\hline 1. & $\begin{array}{l}\text { Reactive } \\
\text { gliosis, } \\
\text { however } \\
\text { low-grade } \\
\text { glioma cannot } \\
\text { be ruled out } \\
\text { (FN) }\end{array}$ & $\begin{array}{l}\text { Low-grade } \\
\text { astrocytoma } \\
\text { (WHO I) }\end{array}$ & $\begin{array}{l}\text { Only serial } \\
\text { sections of one } \\
\text { fragment showed } \\
\text { increased glial cells }\end{array}$ \\
\hline 2. & $\begin{array}{l}\text { Suggestive } \\
\text { of low-grade } \\
\text { glioma; } \\
\text { DD: } \\
\text { meningioma } \\
\text { (FN) }\end{array}$ & Meningioma & $\begin{array}{l}\text { Few meningothelial } \\
\text { cells in FS mistaken } \\
\text { as glial cells }\end{array}$ \\
\hline
\end{tabular}

FS: frozen section, FN: false negative, DD: differential diagnosis 
In this study, out of seven discrepant cases, two discrepant cases were recorded as FP. First FP case was reported as suggestive of high-grade glioma in FS due to the presence of necrotic fragments. However, that necrosis was found to be coagulative necrosis rather than geographic or pseudopalisading necrosis in PS and the case was reported as a low-grade glioma (WHO grade I) (Figures 1 A, B \& C). Cellular proliferation with infarct-like necrosis can be seen in low-grade glioma especially pilocytic astrocytoma. ${ }^{10}$ However, those infarct-like coagulative necrosis and radiation induced necrosis are not surrounded by pseudopalisading tumour cells like in high-grade glioma. ${ }^{3}$ On the other hand, necrosis of glioblastoma can be misdiagnosed as caseous necrosis of tuberculous infection. ${ }^{5,8,11}$ Another error with the second case of FP was due to difficult differentiation of cellularity and misinterpretation of gemistocytes in diffuse astrocytoma (WHO grade II) as pleomorphic cells and reported as suggestive of high-grade glioma in FS. Error in over-grading or under-grading of astrocytoma was also reported in the literature. ${ }^{4,8}$ Over-grading may result in a premature termination of the surgical procedure because the surgeon thinks the diagnostic tissue has been obtained with a grade compatible with the imaging study. ${ }^{3}$

Out of seven discrepant cases in this study, five cases were FN. The other two FN cases was recorded as minor discrepancy as FS were reported as reactive gliosis. Among five discrepant FN cases, four cases were reported as reactive gliosis in FS. Among those four cases reported as reactive gliosis in FS, two cases were found to be low-grade glioma, one case was schwannoma and another was an anaplastic astrocytoma in PS. Differentiation between a low-grade glioma and a reactive gliosis is one of the most difficult diagnostic challenges in FS neuropathology. ${ }^{12}$ In schwannoma case, scattered Schwann cells were mistaken as glial cells during reporting FS. In anaplastic astrocytoma case, tissue section of FS was very small and small atypical tumour cells were misinterpreted as reactive lymphocytes. In that case, irregular naked nuclei of anaplastic tumour cells should be thoroughly examined.

Distinguishing between reactive gliosis and a low-grade glial neoplasm is one of the most difficult differential diagnostic challenges in surgical neuropathology. It is common to find at least some degree of gliosis adjacent to and associated with a tumour. ${ }^{5}$ A study reported that discrepancies in distinguishing reactive gliosis and a low-grade glial neoplasm was $2.3 \%{ }^{12}$ Features such as low cellularity and low nucleocytoplasmic ratio are more in favour of reactive gliosis. ${ }^{13}$

Another FN discrepant case reported as high-grade glioma was non-Hodgkin lymphoma (NHL) in PS. In this case, pleomorphic neoplastic lymphoid cells were mistaken as tumour cells of high-grade glioma (Figures 2 A, B \& C). Discrepancies in the diagnosis of lymphoma in FS are reported in literatures especially the tissue sample is limited, in pre-treated lesions, and in cases with an atypical radiological imaging study. ${ }^{5}$ Sensitivity in the diagnosis of lymphoma in FS is low and it is well known that glioblastomas and metastatic carcinomas histologically can mimic lymphomas. ${ }^{14}$ In case of suspected lymphoma, a cytological smear preparation of the specimen is recommended. ${ }^{15}$ Touch imprint smears exhibit better morphological details without any smearing artefact as compared to FS in the diagnosis of lymphoma. ${ }^{13}$

In this study, two minor discrepant cases were observed. One case was reported as reactive gliosis in FS and low-grade astrocytoma (WHO I) was reported in PS after serial sections of one fragment showed increased glial cells. Another case was reported as suggestive of low-grade glioma with the differential diagnosis of meningioma. It was confirmed as meningioma in PS and it was because few meningothelial cells in FS were mistaken as glial cells. Distinguishing meningiomas, peripheral nerve sheath tumours, and other spindled cell proliferations can be challenging in FS, particularly with limited submitted tissue or tissue distorted by crush artefact or cautery. ${ }^{5}$

Although FS is very useful for neurosurgeons, it is still quite challenging for histopathologists. FS evaluation is not perfect and there are well-known errors and discrepancies that are due to a variety of factors. ${ }^{4} \mathrm{~A}$ study on 2,156 cases of FS diagnosis of brain tumour showed a discrepancy rate of $2.7 \%$ was found with most common discrepancies in the diagnosis of spindle cell lesions, CNS lymphoma, and differentiating oligodendrogliomas from astrocytomas and differentiating reactive gliosis from neoplastic processes. $^{5}$

Agreement between FS and PS varies among histopathological entities and is lower in low-grade 
tumours than in high-grade tumours. Sensitivity for diagnosing CNS lymphomas is low. ${ }^{14}$ In our study, most of the FN cases were low-grade glioma cases and one was NHL. Most of the high-grade lesions showed no discrepancies between FS and PS in this study. However, some study showed disagreement did not relate to any specific tumour type. ${ }^{16} \mathrm{FS}$ are better in diagnosing firmer lesions such as meningioma and schwannoma; and offered better architectural features as compared to cytology. Freezing artefacts were the major drawback, which limited the diagnostic accuracy. Freezing artefacts can be avoided to a large extent by optimal temperature control and rapid freezing of tissue. ${ }^{13}$ Optimal temperature can be achieved by setting the temperature of cryostat between $-15{ }^{\circ} \mathrm{C}$ to $-25{ }^{\circ} \mathrm{C} .{ }^{17}$

In the reporting of FS of CNS lesions, correlation with cytological preparations (both touch imprint smear and squash smear) is widely used. FS and cytological examination of the specimens are complimentary to each other, and both should be used to improve the intraoperative diagnostic accuracy in the CNS lesion. ${ }^{18}$ The cytological touch imprint alone can be diagnostic in the hands of experienced neuropathologists, particularly for meningioma and pituitary adenomas. ${ }^{19}$ In a study, the diagnostic accuracy of squash smears and touch imprints were $89.2 \%$ and $78.4 \%$ respectively, and these were more than the accuracy of FS which was $75.7 \% .{ }^{13}$ The limitation of this study was that cytological smears cannot be reviewed as it was performed only in a few cases with missing cytological smears.

Generally, for FS of all types of tissue, discrepancies between FS and PS reports were due to technical errors, sampling errors and misinterpretations. ${ }^{20}$ In CNS lesion, common causes of discrepancies are sampling errors, technical errors, insufficient or false clinical information and pathologist errors in grading and subtyping of glial tumours. ${ }^{12}$ Communication between the neurosurgeon and pathologist with correct information to be conveyed to the pathologist is very important.

In conclusion, the results of this study showed high accuracy and specificity of FS. Therefore, FS is still useful, effective tool for neurosurgeon although there are some challenges for histopathologists in reporting FS. Over-diagnosis or under-diagnosis of FS can be reduced by closed cooperation among pathologist, neurosurgeon and radiologist.

\section{REFERENCES}

1. Howanitz PJ, Hoffman GG, Zarbo RJ. The accuracy of frozen-section diagnoses in 34 hospitals. Arch Pathol Lab Med 1990; 114(4):355 $-9$.

2. Mahe E, Ara S, Bishara M, et al. Intraoperative pathology consultation: error, cause and impact. Can J Surg 2013; 56(3): E13-8.

3. Prayson RA., Napekoski KM. Introduction. In: Frozen Section Library: Central Nervous System. Frozen Section Library, vol 6. Springer, New York. 2011: 1-8.

4. Prayson RA. Frozen Section Evaluation of Central Nervous System Lesions. In: Hayat MA. Editor, Tumors of the Central Nervous System, Volume 3. Springer Netherlands. 2011; 177-184.

5. Plesec TP, Prayson RA. Frozen section discrepancy in the evaluation of central nervous system tumors. Arch Pathol Lab Med 2007; 131: 1532-40.

6. Raisanen J, White CL III. In: Taxy JB, Husain AN, Montag AG. Editors. Biopsy interpretation: The frozen section (Biopsy interpretation series). $2^{\text {nd }}$ ed. China: Lippincott Williams \& Wilkins; 2014; 378-414.

7. Mat Zin AA, Zulkarnain S. Diagnostic Accuracy of Cytology Smear and Frozen Section in Glioma. Asian Pac J Cancer Prev. 2019;20 (2):321-325

8. Chand P, Amit S, Gupta R, et al. Errors, limitations, and pitfalls in the diagnosis of central and peripheral nervous system lesions in intraoperative cytology and frozen sections. J Cytol 2016; 33: 93-97.

9. Khoddami M, Akbarzadeh A, Mordai A, et al. Diagnostic Accuracy of Frozen Section of Central Nervous System Lesions: A 10-Year Study. Iran J Child Neurol 2015; 9: 25-30.

10. Collins VP, Tihan T, VandenBerg SR, et al. Pilocytic astrocytoma. In: Louis DN, Ohgaki $\mathrm{H}$, Wiestler OD, K. Cavenee WK, Editors. WHO Classification of Tumours of the Central Nervous System. World Health Organization Classification of Tumors. Revised $4^{\text {th }}$ ed. Lyon: IARC Press; 2016; 80-87.

11. Mitra S, Mohan K, Sharma V, et al. Squash preparation: A reliable diagnostic tool in the intraoperative diagnosis of central nervous system tumors. J Cytol 2010; 27: 81-5.

12. Amraei R, Moradi A, Zham H, et al. A Comparison between the Diagnostic Accuracy of 
Frozen Section and Permanent Section Analyses in Central Nervous System. Asian Pacific Journal of Cancer Prevention: APJCP 2017; 18(3): 659-666.

13. Nanarng $V$, Jacob $S$, Mahapatra $D$, et al. Intraoperative diagnosis of central nervous system lesions: Comparison of squash smear, touch imprint, and frozen section. J Cytol 2015; 32: 153-158.

14. Tofte K, Berger C, Torp SH, et al. The diagnostic properties of frozen sections in suspected intracranial tumors: A study of 578 consecutive cases. Surg Neurol Int 2014; 5: 170.

15. Rao S, Rajkumar A, Ehtesham MD, et al. Challenges in neurosurgical intraoperative consultation. Neurol India 2009; 57(4): 464-8.

16. Al-Ajmi R, Al-Kindi $\mathrm{H}$, George $M$, et al. Correlation of Intraoperative Frozen Section Report and Histopathological Diagnosis of Central Nervous System Tumors - A Six-Year Retrospective Study. Oman Med J 2016; 31: 414420.

17. Dey P. Frozen Section: Principle and Procedure. In: Basic and Advanced Laboratory Techniques in Histopathology and Cytology. Springer, Singapore, 2018: 51-55.

18. Sharifabadi AH, Haeri $\mathrm{H}$, Zeinalizadeh $M$, et al. Intraoperative consultation of central nervous system lesions. Frozen section, cytology or both? Pathol Res Pract 2016; 212: 179-84.

19. Powell SZ. Intraoperative consultation, cytologic preparations and frozen section in the central nervous system. Arch Pathol Lab Med 2005; 129: 1635-52.

20. Hatami H, Mohsenifar ZH, Alavi S N. The Diagnostic Accuracy of Frozen Section Compared to Permanent Section: A Single Center Study in Iran. Iran J Pathol 2015; 10(4): 295 - 299. 